CITATION: Bloom, L. (1981). The importance of language for language development: Linguistic determinism in the 1980s. In H. Winitz (Ed.), Native language and foreign language acquisition. Annals of the New York Academy of Sciences (Vol. 379, pp. 160-171). New York: New York Academy of Sciences.

\title{
THE IMPORTANCE OF LANGUAGE FOR LANGUAGE DEVELOPMENT: LINGUISTIC DETERMINISM IN THE 1980s
}

\section{Lois Bloom}
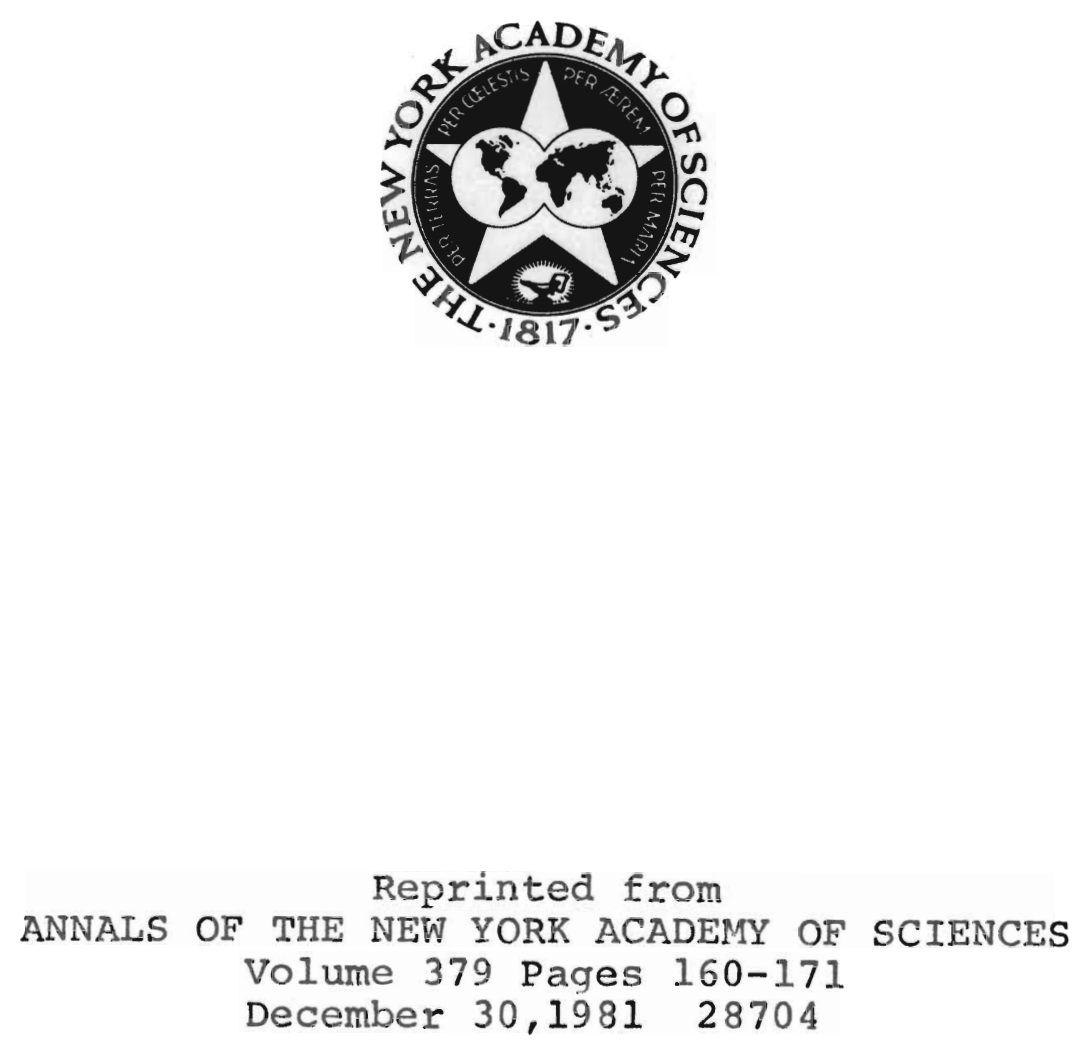

With permission from John Wiley and Sons, Inc., Publisher, 2017. 


\title{
THE IMPORTANCE OF LANGUAGE FOR LANGUAGE DEVELOPMENT: LINGUISTIC DETERMINISM IN THE 1980s *
}

\author{
Lois Bloom \\ Teachers College \\ Columbia University \\ New York, New York 10027
}

Many factors contribute to the process of language development. The child's context, for example, is one source of the meanings of early utterances, inasmuch as children talk about what they do and what they see. The child's social context is one source of the child's communicative intentions, inasmuch as children talk to other persons and learn to use language in the context of social and pragmatic events. And, at the same time, both intentions and meanings are mediated by the child's cognition; what children talk about and how they use language to interact with other persons depend upon what they know. These factors, context and cognition, together contribute in by now obvious ways to language development.

However, one factor that necessarily interacts with these and other factors in less obvious ways is the formal structure of the target language that the child is learning: language is important for language development. The language that children learn-the target language in the child's community-is, itself, a determining factor in how and when the different structures of the language are acquired.

\section{Linguistic Determinism in Child Language}

The importance of language for language development, or linguistic determinism, has been emphasized in different ways in the last several decades. For example, Roger Brown in 1957 demonstrated that the surface forms of the language-in particular, articles $a$ and the, and morphological inflections in English-help the child to learn basic grammatical categories or the part of speech of individual words. ${ }^{1}$ That is, noticing the endings of words, such as -ing, will help the child to determine whether a word names an action or an object. In the 1960s, another version of linguistic determinism originated with the theory of generative grammar and the idea that much of language learning was determined by language universals that somehow were innate. This view was expounded by Noam Chomsky in 1965 and taken up by David McNeill in 1966 and $1970 .^{2-4}$ And, in the 1970 s, the importance of a linguistic determinism that is culturally specific was advanced by Dan Slobin. ${ }^{5}$ Slobin pointed out, for example, that even

* Supported by a research grant from the National Science Foundation. 
though cognitive development most probably does advance in similar ways among children growing up in different environments, the sequence in which children learn to express similar ideas about the world will be determined in large part by the accessibility of the surface forms of the language that express those ideas.

There have been, then, different views of linguistic determinism in the last several decades of child language research-views that have emphasized the surface forms of the language that the child hears; ${ }^{1}$ or the underlying principles oî grammar that are presumed to be universal to all languages; ${ }^{2-4}$ or the surface grammars of different languages that influence the ways in which meaning gets expressed and different orders of acquisition..$^{5,6}$

The purpose of this paper is to present another version of linguistic determinism, one that derives from several recent investigations of child language in the period between two and three years of age. There have been three related themes that have emerged from the results of these studies. To begin with, there are many factors that contribute to the process of language acquisition, so that appeals or explanations or theories based only on cognitive or social or pragmatic factors alone are insufficient. Second, one factor that consistently interacts with all of these other factors is the formal structure of the adult target language. And third, the central feature of the target language that the child is learning that influences the acquisition of increasing linguistic complexity is the verb system, that is, the syntax and semantics of verbs appear to be a major influence on the acquisition of increasingly complex structures.

Thus, while linguistic determinism in the 1950 s emphasized the importance of those linguistic features that identify part-of-speech membership, and linguistic determinism in the 1960s emphasized underlying universal principles of grammar, and linguistic determinism in the 1970 s emphasized differences between languages, linguistic determinism in the beginning of the $1980 \mathrm{~s}$ is pointing to the special role that the verb system plays in acquisition. According to the several studies of child language that are discussed below, the verbs that children learn interact with one or another aspect of linguistic structure to influence how that structure is acquired; in particular, the structure of simple sentences, verb inflections, wh-questions, and complex sentences appears to be mediated by the verb systern of the target language.

\section{Observational, Descriptive Methodology}

The data for these studies consisted of many thousands of dialogues with a small number of children, sometimes four, sometimes up to eight children. Each of the children was visited at home, at periodic intervals, for about five to eight hours of observation. The dialogues of the children with investigators and with parents were recorded and transcribed, with contextual notes, to provide the texts for analysis. The dialogues in these texts were reviewed over and over again so that similarities, consistencies, 
and recurrences among the language behaviors could be identified. Behaviors that occurred again and again in different contexts and with different participants, or behaviors that shared common elements, were grouped together as a potential category of behaviors. Thus, a taxonomy was formed when categories of recurrent behaviors contrasted with one another along some dimension-such as shared meaning, or syntactic relation, or the sequence in which they appear, or their selective use with different linguistic forms.

There are two important features in such an inferential methodology. First, rather than beginning with an intuitive scheme and imposing that organization on the child's behaviors in order to test one or another a priori theory, one observes and describes regularities among children's behaviors in order to discover their organization and build a theory of the child's language. The taxonomy of observed behaviors that emerges from repeated examination of the data is a result rather than a heuristic. Second, in order to infer a pattern of organization from evidence, frequencies of behaviors are compared-both absolute frequency, or simply the number of times a behavior occurs, and relative frequency, or how often a behavior occurs in proportion to all of the child's other relevant behaviors. What is described, then, is regularity among behaviors.

There are four levels of regularity among behaviors. At one level, semantic regularity, utterances are presumed to be semantically similar when there are similarities in the behaviors and situational contexts in the speech events in which they occur. At another level, formal regularity, different forms (such as differences in word order or different $w h$-question words or the different inflections on verbs) are distributed selectively among utterances with different semantic interpretations. At a third level, there is developmental regularity, when the regularities in the behaviors of one child at a single time are systematically related to regularities in the behaviors of the same child at a later time. Finally, at a fourth level, there is regularity among children, when the regularities in behaviors of a single child are consistent with regularities in the behaviors of other children, both at the same developmental level and across time.

An inferential methodology, then, requires observation of large numbers of behaviors-from a single child at one time and at successive times, and from different children. Given a large enough sample of behaviors, patterns of organization can be inferred on the basis of the relative frequencies of different kinds of behaviors and the distribution of behaviors in relation to one another.

\section{From Single Words to Simple Sentences}

One of the most straightforward indications of the essential relation of verbs to the acquisition of syntax is the fact that verbs (as defined for the adult model) are rare in single-word vocabularies before children begin to combine words. The underrepresentation of verbs in the single-word 
utterance period has been well known since Dorothea McCarthy's study of the acquisition of parts of speech. ${ }^{7}$ In attempting to explain the preponderance of nouns in early vocabularies, McCarthy and others have pointed to the high frequency of nouns in the language that children hear, the importance of objects to very young children, and the importance of naming objects for the development of symbolization.

More recently, Nelson reported that a preponderance of nouns (or "general nominals") was not necessarily characteristic of all children in the single-word utterance period, but the words that children learn, if they are not nouns, usually are not verbs either. ${ }^{8}$ At the same time, Bloom pointed out that while children do learn a large number of different noun forms in the period, the words that tend to be used more frequently and in more different situations are words that refer to transformations of objects or relations of objects. ${ }^{9}$ Such relational words in children's vocabularies are not nouns, but they also are not verbs; they include, for example, uhoh, there, up, gone, more, etc. And, in the study by Goldin-Meadow, Seligman, and Gelman, verbs were both produced and understood much less often than nouns by the children studied during the single-word period, and both comprehension and production of verbs increased as the children approached the use of multiword utterances. ${ }^{10}$

The reason for the low frequency of verbs as single-word utterances could not be their relative abstractness (in comparison with nouns, which refer to objects that are literal, more salient events perceptually); such frequent relational words as up, gone, there, and away are as abstract as verbs such as put, make, do, go, and eat. Rather, verbs appear in syntactic contexts when children begin to combine words for multiword utterances. It appears that it is necessary for children to learn verbs in combination with nouns or pronouns, and knowing something about verbs is necessary for the acquisition of grammar. The evidence reviewed here indicates that there is a close relation between learning verbs and learning the grammar of the basic phrase structure of sentences.

Once multiword utterances begin, the verbs that children learn in syntactic combination appear to be constrained categorically. That is, children do not learn a garden variety assortment of verbs, with combinations of words dependent upon the idiosyncratic possibilities of particular, individual verbs for the relations between words. Rather, children seem to learn global or molar categories of verbs that share syntactic or semantic features, so that there is consistency among the relations between words. For example, the verbs read, eat, and ride are related to one another because they name actions and participate in the same semantic/syntactic relation with actor nouns (e.g., Mommy read, Daddy eat, Baby ride). Further, different relations with the same verb are, themselves, related to one another systematically (for example, Mommy read, read book, Mommy book; Daddy eat, eat raisin, Daddy raisin; and Baby ride, ride bike, Baby bike). Categorical differences among verbs include, for example, the syntactic distinction between transitive verbs (e.g., read, eat) and intransi- 
tive verbs (e.g., dance, run); the semantic distinction between verbs of action (e.g., eat, dance, run) and verbs of state (e.g., want, know, see); and the semantic-syntactic difference between verbs that entail locative constituents to complete their meaning (e.g., put, go, sit) and those that do not. ${ }^{13,19}$

\section{Transitive and Intransitive Verbs in Simple Sentences}

One of the broadest distinctions among verbs, the syntactic difference between transitive and intransitive verbs; appears to differentiate among children in the beginning stages of syntax, when the first sentences with verbs appear with some regularity. Certain children have used intransitive verbs primarily (e.g., jump, sing, run) ${ }^{11,12}$ The syntax of sentences with such verbs entails only one constituent relation: noun (actor) + verb (intransitive action). In contrast, other children have used transitive verbs primarily (e.g., eat, read, find)..$^{13-15}$ The syntax of sentences with transitive verbs entails the relations among subject, verb, and complement, and more than one constituent relation theoretically is possible. For example, the children studied by Bloom et al. produced early sentences with the separate constituent relations subject-verb (Mommy read), verb-object (read book), and verb-place (put chair), object-place (sweater chair). ${ }^{16,13}$

Thus, there is some evidence that the first break into syntax appears to be guided by the combinatorial possibilities that several different verbs have in common as either transitive or intransitive verbs. Different children apparently begin syntax by learning to combine words with verbs that share one or the other of these syntactic possibilities, with a generalized rule of grammar that is particular to that class of verbs. The fact that one or another syntactic category of verbs predominates in the early syntax of different children is one indication of the way in which distinctions among verbs in the adult target language influence acquisition.

The distinction between transitive and intransitive verbs in children's early word combinations was apparent when the results of several studies by different investigators were compared. Other indications of the importance of the target language for language development, and, in particular, the importance of verbs, have come from the results of a longitudinal investigation of the language development of eight children, which have been reported elsewhere in the literature by Bloom et al. ${ }^{16,13}$

There were three kinds of complexity that the children added to their simple sentences when the mean length of utterance of their sentences passed 2.0 morphemes in the period between two and three years of age. The children began to add inflectional endings to verbs (-ing, $-s$, -ed, and irregular past); they began to ask questions with the $w h$-question words what, where, who, how, why, and when; and they also began to combine the structures underlying simple sentences in order to form complex sentences with the syntactic connectives and, then, because, what, but, so, and that. Each of these three kinds of increased complexity in the children's 
language was influenced by the verbs that the children knew and were learning.

\section{Verb Semantics and Verb Inflections}

In a study of the emergence of verb inflections, the relationship between the syntax and semantics of the verbs used in early sentences and the emergence of the inflectional forms of the verb auxiliary (-ing, $-s$, -ed, or irregular past) was explored. ${ }^{17}$ In earlier discussions of the acquisition of grammatical morphemes, only the syntax and semantics of the individual morphemes themselves (along with their environmental frequency) had been discussed seriously as contributing to the order in which grammatical morphemes are acquired. ${ }^{14,18}$ However, the results of this study suggested that the semantic organization of the verb system that children learn is at least as important as the meanings of the morphemes themselves for determining the acquisition of the inflections of verbs.

The different inflections (ing, $s$, and ed or irregular past) emerged in the children's speech at the same time when the mean length of utterance (MLU) was about 2.0. However, both the syntax of the children's sentences with different verbs and the semantics of verbs interacted selectively with the use of different inflections. First, with respect to the syntax of sentences, there were several categories of verbs in the children's speech that were identified according to whether a locative constituent was entailed in the meaning of the verb (action and locative action verbs) and according to the semantic relation between different locative action verbs and the sentence subject (whether the sentence subject functioned as agent, mover, or patient in the change of place that was named by the verb) ${ }^{19}$ If there was no interaction between the syntax of sentences and the inflections of verbs, then one could expect that the relative frequency of the use of inflections would match the relative frequency of sentences that occurred with these different kinds of verbs. That is, there should not be a difference between the relative distribution of sentences with the different categories of action and location action verbs, and the relative distribution of the use of inflections among these sentences. In fact, however, there were statistically significant differences between the distribution of sentencesor relative frequency of sentences that occurred with different categories of verbs - and the distribution of the use of inflections among those sentences with different verbs. Thus, the syntax of the sentence helped to determine whether the verb was inflected.

Further, only a few of the verbs that were inflected occurred with all of the different verb inflections. These were the verbs do, go, and make, a small group of verbs that were used with great frequency by all of the children; they were more general in reference than descriptive verbs such as ride, turn, and drink and appeared to function as pro-verbs. But, while all of the possible verb inflections occurred with these semantically general pro-verbs, each of the inflections occurred selectively with different popu- 
lations of descriptive verbs. Certain descriptive verbs occurred almost exclusively with -ing; certain other verbs occurred almost exclusively with past tense (irregular or regular $-e d$ ); and certain other verbs occurred only with $-s$.

The selective distribution of descriptive verbs with the different inflections coincided with the intersection of two of the most fundamental distinctions of verb aspect: duration and completion. Aspect is the temporal contour of an event that is named by a particular verb-such as an action that is momentary in time (e.g., hit or jump) in comparison with an action that is durative and lasts over time (e.g., eat or play), and an action that entails completion or an end result (e.g., break) in comparison with an action that does not entail a result (e.g., swim). The verbs that occurred with -ing named aspectual events that were both durative (that is, they lasted over time) and noncompletive (in that they did not entail an end result), for example, playing, riding, reading, and swimming. The verbs that occurred with regular -ed or irregular past named events that were both nondurative (or punctual and momentary in time) and completive (with an end result), for example, broke, found, and pushed. Finally, the verbs that occurred with $-s$ named events that were both durative and completive, for example, goes and fits.

The semantics of verb aspect appeared to be the major factor that governed the emergence of verb inflections in these children's speech. The children's use of inflections was redundant in relation to the inherent aspectual meanings of their verbs inasmuch as the inflections themselves carry the same durative and completive aspectual meanings. That is, adults add -ing to a nondurative verb to indicate repetition or duration (e.g., hitting, jumping) or use the past form of otherwise durative verbs to indicate completion (as in "she swam a mile"). The children learned to use the inflections to mark tense, that is, to mark the deictic relations between event time and speech time, sometime after they used the forms for redundant coding of aspect. This developmental sequence of coding aspect before tense is consistent with results reported in experimental studies of the use of inflections by somewhat older children; ${ }^{20,33,34}$ and it confirms the general principle of aspect before tense proposed by Eric Woisetschlaeger for the morphology of adult languages. ${ }^{21}$ The children's early use of inflections was verb specific in that they learned the different inflections with semantically different populations of verbs.

\section{Verbs and the Sequence of Wh-Questions}

Yet another interaction between the verb system and the development of complexity in the children's language was observed in the acquisition of wh-questions. ${ }^{22}$ The children asked about 8,000 wh-questions in the period from about 22 to 36 months of age and learned to ask wh-questions with verbs in the order what $>$ where $>$ who $>$ how $>$ why $>$ when. This essentially is the same order that has been observed in other studies as well (for both 
answering and asking $w h$-questions). There were structural differences among these questions that corresponded to their sequence of acquisition. The first wh-questions, what, where, and who, are wh-pronominals that ask for major sentence constituents-object (what), place (where), subject (who) - and are relatively simple syntactically. In contrast, why, how, and when, which emerged later, are wh-sententials, which do not replace major sentence constituents, but ask for information that pertains to the semantic relations among all the constituents in the sentence. The sequence in which the $w h$-forms were acquired, then, reflected the relative syntactic complexity among different $w h$-forms.

In addition, there also was a differential use of wh-questions with different populations of verbs. Apart from questions with the contracted and uncontracted copula, there was a small group of verbs, the pro-verbs do, go, and happen, that were the most frequent verbs that the children used in wh-questions. These general, all-purpose pro-verbs, and the copula, occurred overwhelmingly with the early wh-question words what, where, and who. In contrast, the later-appearing questions how, why, and when occurred primarily with descriptive verbs that named particular actions and states. Thus, there was an interaction between the syntactic function of the individual $w h$-words and the semantic complexity of the verbs that were used with each question form. The pronominal $w h$-forms that asked for sentence constituents (what, where, who) occurred predominantly with pro-verbs, whereas the sentential forms (how, why, when) occurred predominantly with descriptive verbs. It was apparent that the order of acquisition of the $w h$-forms covaried with both the syntax of $w h$-questions and the kind and variety of verbs.

It appears that the sequence in which these children learned to ask different $w h$-question forms was determined in part by complications having to do with learning to use main verbs for asking questions. As proforms for major sentence constituents, the earliest-learned wh-question forms (what, where, who) can be combined more easily with the verb proforms (the copula, do, or go) without the child having to sort out the individual semantic and syntactic constraints between different descriptive verbs and nouns. In contrast, why, how, and when are wh-sententials that do not replace major sentence constituents; the meaning of these forms interacts with sentential meaning. They were used with descriptive verbs primarily, and they were acquired later. In addition, then, to whatever cognitive constraints and whatever motivational and functional factors contribute to the developmental sequence of $w h$-questions, there evidently are important linguistic constraints: in particular, constraints that operate in the selection of verbs with different $w h$-question words.

\section{Verbs and Complex Sentences}

A major feature of the children's later language development (after the development of simple sentences and along with the development of 
inflections and wh-questions that has been discussed so far) is the development of complex sentences with connectives. ${ }^{23}$ Three syntactic structures have been observed in the children's complex sentences in the developmenta! sequence conjunction $>$ complementation $>$ relativization, and each of the syntactic structures developed with essentially different populations of verbs. Examples of conjunction were "maybe you can carry that and I can carry this" (additive conjunction); "you push that up and it turn" (temporal conjunction); "get them cause I want it" (causal conjunction); and "I was tired but now I'm not tired" (adversative conjunction). Conjunction, which was the most frequent kind of complex sentence, occurred with many different action and locative action verbs and with relatively few state verbs. ${ }^{23}$

Relativization-for example, "that's the man who fixes the door"occurred most often with the contracted or uncontracted copula is in the main clause. In contrast with conjunction, which used action and locative action verbs primarily, and relativization, which used the copula primarily, the third complex sentence structure to develop, complementation, used state verbs most of the time-for example, "I don't know what her name is" - or, less often, the contracted copula-for example, "That's what you can do." The complementation that the children learned was constrained by semantically specific state verbs: volitional and intentional verbs (want, like, need); epistemic verbs (know and think); notice verbs (see, look, show, watch); and communication verbs (say, tell)..$^{24}$ Complementation verbs were acquired by the children in the order volition $>$ notice $>$ epistemic $>$ communication. ${ }^{24}$ Similar complementation verbs have been reported for other children and appear to be the semantic antecedents of the verbs used by adults for complementation..$^{25,26}$

The children's verbs were distributed in complex sentences, then, in the following way: conjunction occurred overwhelmingly with action and locative verbs; relativization occurred primarily with the copula is; complementation occurred overwhelmingly with state verbs, with semantic subcategories of state verbs acquired sequentially.

\section{The Importance of Verbs in Child Language}

The importance of verbs in language has been underscored in both psychological accounts of sentence processing and linguistic accounts of grammatical theory. ${ }^{27-31}$ The results of the several child language studies that have been described here have led to the following conclusions about the importance of verbs in language acquisition. First, the child's mental lexicon probably is different for nouns and verbs. With respect to the child's expanding mental lexicon, the studies reviewed here suggest that there probably are not separate entries for verbs in a mental lexicon as there probably are for nouns. The fact that nouns are learned one by one appears to be preserved in most accounts of the way that information about 
nouns is stored in memory. If children's knowledge of verbs similarly retains information from the way in which verbs are learned originally, then it may not be appropriate to think in terms of a verb lexicon per se. Lexical verb development and grammatical development appear to be mutually dependent, with the result that the child's verb lexicon is not simply part of a mental dictionary with all the words that a child knows, including nouns. Rather, the results of the studies described here suggest that the verb system in child language may consist of a categorization of verbs on several levels of rules of grammar, with a network of attachments to a noun lexicon. Verbs are learned and exist along with the rules for grammar that determine the basic structure of sentences, and children's knowledge of language structure probably never is independent from the different verbs they know.

The categorization of verbs that has emerged from our studies includes large, molar categories-action/state; locative/nonlocative; durative/ nondurative; completive/noncompletive; volitional/epistemic/notice/communication states, etc. The claim for the psychological and linguistic reality of these semantic categories rests on their being coextensive with major grammatical developments in the children's language, or on their sequential development. There has been no evidence that more molecular semantic categories - such as verbs of locomotion (run, walk, skip, fly, etc.) or verbs of ingestion (eat, drink, swallow, slurp, chew, etc.)-have the same psycholinguistic status in these children's early language learning. Such potential molecular categories appear to be represented in the early child speech data by only one or a few instances (e.g., eat for the larger category of ingestion; ride and run for the larger category of locomotion; say and tell for the larger category of communication, etc.). Thus, there often were only a few verbs in one or another category that occurred with great frequency, as though the children had learned the relevant linguistic form or structure with a few verb exemplars and the high-frequency proverbs, such as do and go, which they used generally, as they learned a wider range of more semantically specific verbs. Knowing the structure, the children then would be able to fill in and expand the verb categories to form more molecular categories. Certain molecular categories may be relevant, however, for language learning in other cultures, as for instance appears to be the case for verbs of possession and exchange in the acquisition of Kaluli, a non-Austronesian ergative language of New Guinea, as reported by Bambi Schieffelin. ${ }^{32}$

To conclude, it has become increasingly clear that the structural complexity, both syntactic and semantic, of the target language is a critical factor that contributes to its acquisition. ${ }^{9,5,6}$ The results of the several child language studies that have been reviewed here provide substantial support for a model of language development that emphasizes linguistic complexity and, in particular, the syntactic and semantic functions of verbs as major factors that contribute to the cognitive requirements for learning language. 


\section{ACKNOWLEDGMENTS}

An expanded version of this paper, "The Semantics of Verbs in Child Language," was presented as an Invited Address to the Eastern Psychological Association, Washington, D.C., 1978. The present title leans on the title of the recent paper by Dan I. Slobin, "The Role of Language in Language Acquisition." ${ }_{6}$ I thank Joanne Bitetti Capatides for helpful comments on an early draft of the paper.

\section{REFERENCES}

1. Brown, R. 1957. Linguistic determinism and the part of speech. J. Abnorm. Psychol. 55: 1-5.

2. Chomsky, N. 1965. Aspects of the Theory of Syntax. MIT Press. Cambridge, Mass.

3. MCNeILl, D. 1966. Developmental psycholinguistics. In The Genesis of Language. F. Smith \& G. Miller, Eds.: 15-84. MIT Press. Cambridge, Mass.

4. McNeILl, D. 1970. The Acquisition of Language: The Study of Developmental Psycholinguistics. Harper and Row Publishers, Inc. New York, N.Y.

5. Slobin, D. 1973. Cognitive prerequisites and the development of grammar. In Studies of Child Language Development. C. Ferguson \& D. Slobin, Eds.: 175-208. Holt, Rinehart \& Winston. New York, N.Y.

6. Slobin, D. I. 1979. The role of language in language acquisition. Invited Address. Eastern Psychological Association. Washington, D.C.

7. MCCarthy, D. 1930. The language development of the preschool child. Institute of Child Welfare Monograph No. 4. University of Minnesota Press. Minneapolis, Minn.

8. Nelson, K. 1973. Structure and strategy in learning to talk. Monogr. Soc. Res. Child Dev. 38.

9. Bloom, L. 1973. One Word at a Time: The Use of Single-Word Utterances Before Syntax. Mouton. The Hague, the Netherlands.

10. Goldin-Meadow, S., M. Seligman \& R. Gelman. 1976. Language in the two-year old: receptive and productive stages. Cognition 4: 189-202.

11. Bowerman, M. 1973. Early Syntactic Development: A Cross-Linguistic Study with Special Reference to Finnish. Cambridge University Press. Cambridge, England.

12. Lightbown, P. 1977. Consistency and variation in the acquisition of French: a study of first and second language development. Doctoral Dissertation. Teachers College. Columbia University. New York, N.Y.

13. Bloom, L., P. Lightbown \& L. Hood. 1975. Structure and variation in child language. Mongr. Soc. Res. Child Dev. 40.

14. Brown, R. 1973. A First Language, the Early Stages. Harvard University Press. Cambridge, Mass.

15. PARK, T. Z. 1970. The acquisition of German syntax. Working Paper. University of Munster. Munster, Federal Republic of Germany.

16. Bloom, L. 1970. Language Development: Form and Function in Emerging Grammars. MIT Press. Cambridge, Mass.

17. Bloom, L., K. Lifter \& J. Hafitz. 1980. Semantics of verbs and development of verb inflections in child language. Language 56: 386-411.

18. DE Villiers, J. G. \& P. A. DE Villiers. 1973. A cross-sectional study of the acquisition of grammatical morphemes. J. Psycholinguistic Res. 2: 267-278.

19. Bloom, L., P. Miller \& L. Hood. 1975. Variation and reduction as aspects of competence in language development. In Minnesota Symposia on Child 
Psychology. A. Pick, Ed. 9: 3-55. University of Minnesota Press. Minneapolis, Minn.

20. Bronckart, J. P. \& H. Sinclair. 1973. Time, tense, and aspect. Cognition 2: $107-130$.

21. Woisetschlaeger, E. 1976. A semantic theory of the English auxiliary system. Doctoral Dissertation. Massachusetts Institute of Technology. Cambridge, Mass. (Reproduced by the Indiana University Linguistics Club. Bloomington, Ind.)

22. Bloom, L., S. Merkin \& J. Wootten. Wh-questions: linguistic factors that contribute to the sequence of acquisition. (Submitted.)

23. Bloom, L., M. Lahey, L. Hood, K. Lifter \& K. Fiess. 1980. Complex sentences: acquisition of syntactic connectives and the semantic relations they encode. J. Child Lang. 7: 235-261.

24. Bloom, L., J. Hafitz \& B. Gartner. Development of sentence complementation. (In preparation.)

25. Limber, J. 1973. The genesis of complex sentences. In Cognitive Development and the Acquisition of Language. T. Moore, Ed.: 169-185. Academic Press, Inc. New York, N.Y.

26. Rosenbaum, P. S. 1967 The Grammar of English Predicate Complement Constructions. MIT Press. Cambridge, Mass.

27. ThORNDyke, P. W. \& G. H. Bower. 1974. Storage and retrieval processes in sentence memory. Cognitive Psychol. 6: 515-543.

28. Wanner, E. \& M. Maratsos. 1978. An ATN approach to comprehension. In Linguistic Theory and Psychological Reality. M. Halle, J. Bresnan \& G. Miller, Eds.: 119-161. MIT Press. Cambridge, Mass.

29. BRESNAN, J. 1978. A realistic transformational grammar. In Linguistic Theory and Psychological Reality. M. Halle, J. Bresnan \& G. Miller, Eds.: 1-59. MIT Press. Cambridge, Mass.

30. Chafe, W. 1971. Meaning and Structure of Language. University of Chicago Press. Chicago, Ill.

31. Fodor, J. A., M. Garrett \& T. G. Bever. 1968. Some syntactic determinants of sentential complexity. II. Verb structure. Percept. Psychophys. 3: 453-461.

32. Schieffelin, B. 1979. How Kaluli children learn to think, feel and act. Doctoral Dissertation. Teachers College. Columbia University. New York, N.Y.

33. Harner, L. Children talk about the time and aspect of action. Child Dev. (In press.)

34. SмrтH, C. 1980. The acquisition of time talk: relations between child and adult grammar. J. Child Lang. 7: 263-278. 


$-$ 